\title{
ENERGY
}

\section{Possibilities for gas turbine and waste incinerator integration}

\author{
M.A. Korobitsyn ${ }^{\mathrm{a}, *}$, P. Jellema ${ }^{\mathrm{b}}$, G.G. Hirs ${ }^{\mathrm{b}}$ \\ a Netherlands Energy Research Foundation ECN, PO Box 1, NL-1755 ZG Petten, The Netherlands \\ ${ }^{\mathrm{b}}$ Department of Mechanical Engineering, University of Twente, PO Box 217, NL-7500 AE Enschede, \\ The Netherlands
}

Received 29 January 1999

\begin{abstract}
The aggressive nature of the flue gases in municipal waste incinerators does not allow the temperature of steam in the boiler to rise above $400^{\circ} \mathrm{C}$. An increase in steam temperature can be achieved by external superheating in a heat recovery steam generator positioned behind a gas turbine, so that steam of a higher energy content becomes available for electricity production. The paper addresses two basic schemes. In one case, steam generated at a waste-to-energy plant is superheated in a combined-cycle plant that operates in parallel. In the other case, the exhaust from a gas turbine plant is sent through a superheater section to the waste incinerator's boiler providing preheated combustion air. Performance of these configurations together with two modified schemes was analyzed in terms of efficiency, natural gas consumption and boiler surface area. An exergy analysis of the cases was carried out. The results showed that the integrated options can effect a substantial increase in efficiency. The hot windbox configuration was found the most effective solution, offering a smaller boiler surface area along with a moderate rate of natural gas consumption. (C) 1999 Elsevier Science Ltd. All rights reserved.
\end{abstract}

\section{Introduction}

Of waste processing technologies such as landfill, composting, or recycling, incineration remains the most effective volume reducing technology. It also can manage disposal of various wastes, such as combustible solids, semi-solids, sludge, liquid wastes, and gases. The postcombustion systems of an incineration plant control undesirable airborne emissions. Dioxin formation is minimized by improved boiler geometry and flue gas recirculation to ensure complete burn-out of carbon, the remaining dioxins are removed by activated carbon filters or by catalytic oxidation.

The heat released from combustion can be recovered in a boiler to supply steam to a steam

\footnotetext{
* Corresponding author. Fax: +31-22456-3504.

E-mail address: korobitsyn@ecn.nl (M.A. Korobitsyn)
} 
turbine, or for process needs. In this way Switzerland, Luxembourg and Denmark recover energy from over $70 \%$ of their waste [1]. An incineration plant can process as much as 2500 tons of refuse per day [2]. Heat recovery and power generation have become a common practice at incineration plants, and many waste-to-energy (WTE) plants have been built around the world [3-6]. Advanced MSW treatment technologies such as pyrolysis and gasification allow even more effective waste utilization resulting in less secondary wastes (emissions, ashes, residues). Siemens offers pyrolysis combined with combustion and subsuquent steam generation. A commercial plant of 150000 ton/year was built in Fürth, Germany [7]. Another technology is developed by Thermoselect. It consists of three stages: compression of waste, its pyrolysis, and oxygen-blown gasification with production of a synthesis gas [8]. The syngas is fed into a gas engine or supplied as a feedstock for methanol production. The first commercial plant at Karlsruhe in Germany of 225000 ton/year is scheduled for operation in 1999. A general overview of advanced thermal treatment technologies can be found in Refs. $[9,10]$. Nevertheless, the classical grate combustion remains the dominating technology represented by more than $90 \%$ of the waste incineration market.

The composition of the municipal solid waste (MSW) varies considerably and depends on many factors, such as location, local policy, origin of the waste, etc. Typical waste consists of: paper and paperboard $20-40 \%$ by mass, garden and food wastes $20-35 \%$, wood 2-6\%, plastic 6-10\%, textile $2-6 \%$, glass $3-8 \%$, metals $3-10 \%$, and inert matter up to $10 \%[2,4]$. The lower heating value of the waste varies accordingly from 6 to $14 \mathrm{MJ} / \mathrm{kg}$. The magnitude of the heating value affects the ratio between primary and secondary air in the incinerator. For waste with a low heating value, the primary air constitutes $80 \%$ of the total air flow, while for waste of high and medium heating value, the percentage lies between $50 \%$ and $70 \%$.

In order to avoid slag deposits, erosion and corrosion in the boiler, and to maintain a sufficient residence time for after-burning, several arrangements in the boiler design should be provided. The evaporator's tubing is to be located in the second pass, the superheater's tube bundles in the second or the third pass, where flue gas temperature drops to an acceptable level. The surface temperature of the tubes can be adjusted with the use of a de-superheater.

The flue gas, passing through the boiler, is cooled from $1000^{\circ} \mathrm{C}$ in the radiation section to $600-$ $800^{\circ} \mathrm{C}$ at the entrance of the convection area. After passing the evaporator's bundles the gas flows through the superheater and economizer (Fig. 1). The aforementioned precautions result in a relatively low temperature of the superheated steam of around $400^{\circ} \mathrm{C}$. On the other hand, temperature of the flue gas in the stack should not drop below $200^{\circ} \mathrm{C}$ due to the risk of condensation of aggressive compounds. These limits constrain the high efficiency of the MSW incineration boiler. Some improvement of the cycle can be achieved by raising the temperature of the steam externally or by preheating the combustion air, or both.

\section{Gas turbine integration}

The high temperature of a gas turbine's exhaust makes it well-suited to integration with an MSW incinerator. Exhaust heat can be recovered in the waste heat boiler where further superheating of steam coming from the incinerator takes place. Utilization of gas turbine exhaust heat as preheated combustion air is another possible integration scheme. 


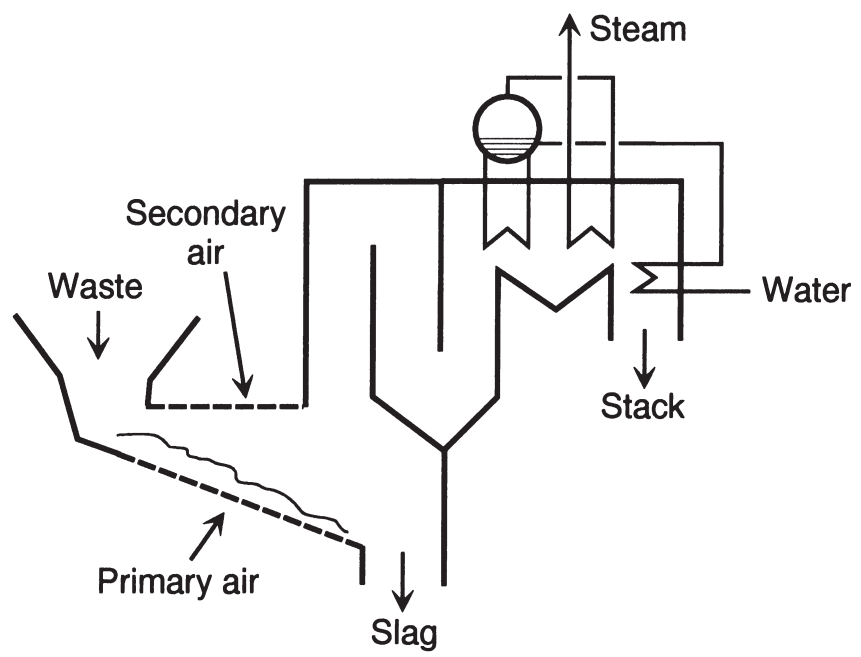

Fig. 1. Simplified solid waste incinerator schematic (Reference case).

Plant configurations, where the heat recovery steam generator (HRSG) operates in parallel with the incineration boiler, are described in the literature: the lower temperature steam from the incinerator can be passed either to the intermediate pressure section of a steam turbine [5], or be further superheated in the HRSG [11,12]. In the latter configuration, the integrated plant was reported to have a $2.2 \%$ higher efficiency than the mean efficiency of two separate plants. However, in the both integrated configurations, the gas turbine plays a dominant role, consuming up to $80 \%$ of the fuel input.

Another approach is to use of the gas turbine exhaust as the inlet flow for the incinerator's furnace. This concept is often used for steam plant repowering. An improvement in the total plant efficiency by $10-20 \%$ together with up to $28 \%$ power increase can be obtained $[13,14]$.

The gas turbine exhaust contains $14-16$ vol\% oxygen, compared to $21 \mathrm{vol} \%$ in the air. Thus, in order to provide the same amount of oxygen to the boiler, a 30\% larger flow from the gas turbine is required. At the same time, exhaust heat reduces heat demand in the boiler, and less oxygen is needed. Davidse and Roukema [15] estimated that the gas turbine flow should be about $106 \%$ of the normal air flow for the same heat load in the boiler's furnace. Considering the combustion of waste, the exhaust flow should have a pressure high enough to pass air through the waste layer on the grates. This can be accomplished either by the use of air blowers or by expansion to a pressure above the atmospheric level.

Such a hot windbox configuration is dependent on the gas turbine performance. A gas turbine trip can affect the steam boiler reliability, therefore, some precautions should be made. For example, air fans can be kept in a stand-by position, or operated in parallel with the gas turbine. To reduce thermal stress in the windbox when switching from hot exhaust gas to air, steam air heaters or back-up burners can be installed [13]. When the gas turbine flow is too large for a given boiler, part of the flow can be bypassed to a stack, or to the convection section of the boiler.

The performance of the hot windbox scheme can be further improved, if external superheating is applied. If the steam from the incineration boiler is passed to a superheater located in the gas turbine exhaust duct, where it is not exposed to the corrosive gases, steam temperatures higher 
than $400^{\circ} \mathrm{C}$ can safely be achieved. The superheater has a simpler design and a much smaller surface area than a heat recovery boiler, while increasing the steam temperature to the same level as that in the HRSG.

\section{Configurations}

To estimate the effect of gas turbine integration in different configurations, integrated plants were compared with a conventional MSW incinerator. The amount of waste being processed by all plants was assumed to be 230000 tons of solid waste per year, or 33 tons per hour. This amount of refuse is equal to a fuel input of $92 \mathrm{MWth}$, if the lower heating value of the waste averages $10 \mathrm{MJ} / \mathrm{kg}$. The composition of the waste is presented in Table 1 . The specifications of the reference incineration plant, the gas turbine plant based on a General Electric Frame 6 turbine, and the heat recovery steam generator are given in Table 2. The simulation models based on the gas turbine were scaled to have the same fuel (waste) input for comparison analysis.

Case 1 represents a combination of a gas turbine plant with a heat recovery steam generator and a waste incinerator. The steam coming from the incineration plant is passed to the HRSG, where it is superheated to $520^{\circ} \mathrm{C}$, and then sent to the steam turbine (Fig. 2).

Since the exhaust from the HRSG has a temperature of $80-100^{\circ} \mathrm{C}$, this heat can be utilized in the incineration boiler as secondary air. This modification of the previous case is referred to as Case 2. In Case 3, the gas turbine exhaust heat is partially recovered in a superheater, following which it is passed to the MSW incinerator (Fig. 3). In this configuration a large steam flow from the incineration boiler does not allow the steam temperature in the superheater to rise above $486^{\circ} \mathrm{C}$. Thus, another scheme with an HRSG and an exhaust bypass is considered. The schematic of this case is given in Fig. 4. Here, a superheat of $520^{\circ} \mathrm{C}$ can be achieved by controlling the amount of the flue gas that is directed to the furnace via the bypass. By doing this, the HRSG generates less steam and because of the reduced mass flow a higher temperature can be obtained in the superheater.

In all integrated configurations the steam pressure in the incineration boiler was raised from 40 bar to $80-100$ bar in order to take full advantage of superheating.

Table 1

Composition of the municipal solid waste

\begin{tabular}{lclc}
\hline Mass $\%$ & Molar\% & \\
\hline Garden and food waste & 30.0 & Carbon & 31.24 \\
Paper and paperboard & 29.0 & Hydrogen & 4.28 \\
Plastic & 12.0 & Oxygen & 17.83 \\
Glass & 3.0 & Nitrogen & 0.96 \\
Metal & 3.0 & Sulfur & 0.17 \\
Textile & 6.0 & Phosphorus & 0.10 \\
Combustibles & 12.0 & Chlorine & 0.95 \\
Non-combustibles & 5.0 & Water & 26.90 \\
& & Ash & 17.57 \\
\hline
\end{tabular}


Table 2

Plant incineration

Waste incineration boiler:

HP steam

40 bar, $400^{\circ} \mathrm{C}$

LP steam

3.7 bar, saturated

Condenser pressure

$0.1 \mathrm{bar}$

Deaerator pressure

Minimum stack temperature

Combustion efficiency

3.5 bar

$200^{\circ} \mathrm{C}$

ST isentropic efficiency

0.96

Gas turbine:

Net power output

0.85

Efficiency (LHV)

$38 \mathrm{MW}$

0.319

Exhaust temperature

$545^{\circ} \mathrm{C}$

Exhaust flow

$139.4 \mathrm{~kg} / \mathrm{s}$

HRSG:

Approach temperature

$15 \mathrm{~K}$

Pinch temperature

$25 \mathrm{~K}$

Heat transfer coefficients:

- economizer

$65 \mathrm{~W} / \mathrm{m}^{2} \mathrm{~K}$

- evaporator

$55 \mathrm{~W} / \mathrm{m}^{2} \mathrm{~K}$

- superheater

$35 \mathrm{~W} / \mathrm{m}^{2} \mathrm{~K}$

Superheater temperature

$520^{\circ} \mathrm{C}$

Minimum stack temperature

$80^{\circ} \mathrm{C}$

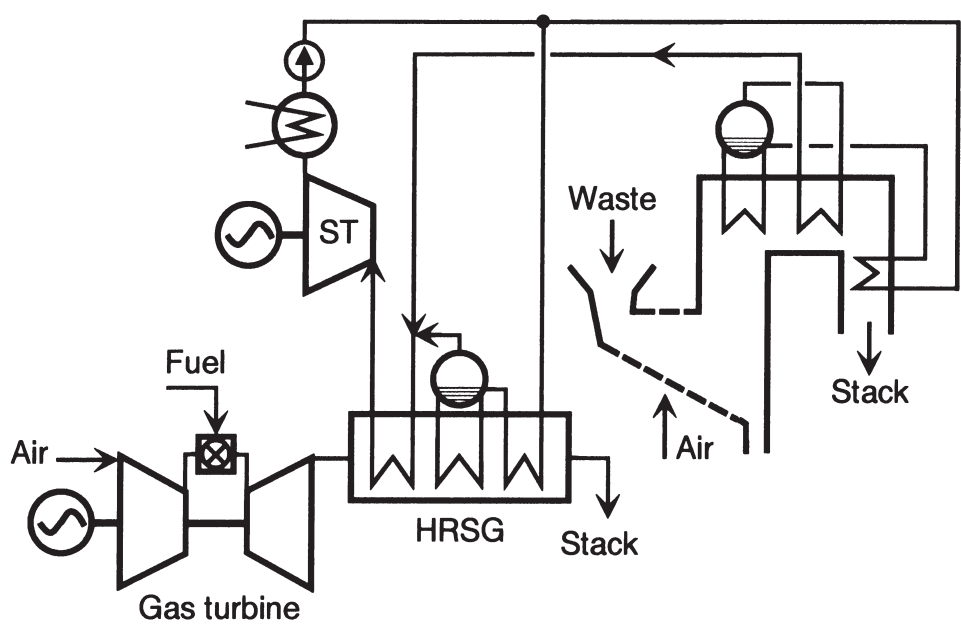

Fig. 2. HRSG-Incineration boiler parallel configuration (Case 1).

The cases were simulated using GateCycle heat balance software package [16]. The simulations were made under ISO conditions $\left(15^{\circ} \mathrm{C}\right.$, relative humidity $60 \%$, sea level). Pressure losses in heat exchangers and through the waste combustion grates, blow-down, and deaerator vent flows were not taken into account. Internal consumption, which constitutes $12-15 \%$ of the total power generated, was omitted as well. Thus, only gross efficiency is given in the analysis. 


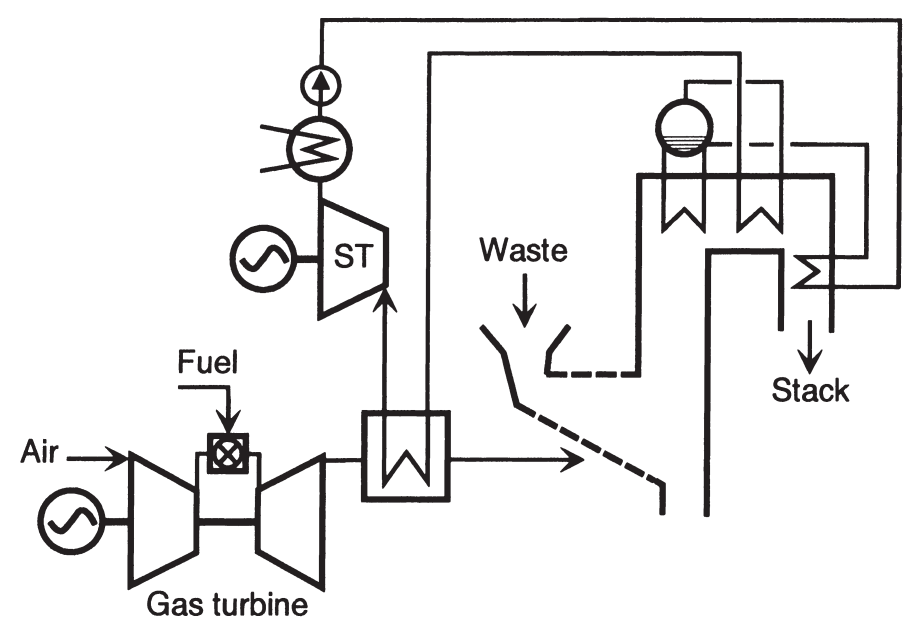

Fig. 3. The hot windbox configuration with superheating (Case 3).

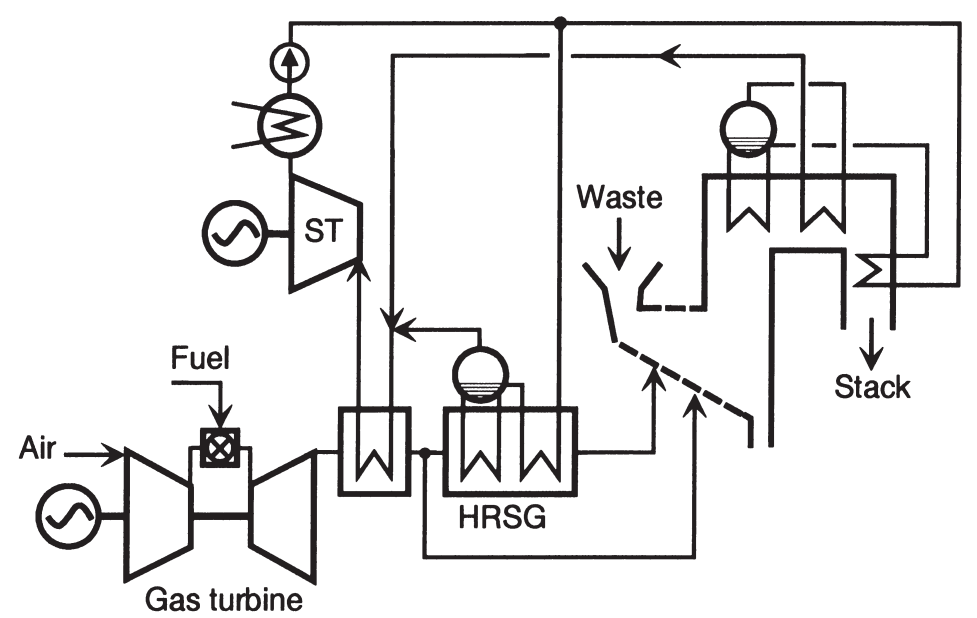

Fig. 4. HRSG-Incineration boiler parallel configuration with an exhaust bypass (Case 4).

\section{Performance analysis}

The results of the analysis showed that integration of an MSW incinerator with a gas turbine plant leads to a significant increase in efficiency. The gross plant efficiency (based on LHV) improved from $24.9 \%$ in the reference case up to $37.3 \%$ in Case 3 and $41.3 \%$ in Case 4 . As shown in Table 3 this figure is due to the gas turbine contribution, which consumes to $53.2 \%$ of the total fuel input. The use of the HRSG exhaust as the secondary combustion air in Case 2 had a little effect on the total efficiency due to its rather low temperature: the difference between Case 1 and Case 2 is only $0.2 \%$ points. Case 4, where an exhaust bypass is employed in order to rise the superheated steam temperature, has the best overall efficiency of $41.3 \%$, however at the expense of the highest natural gas consumption rate. 
Table 3

Summary of results (scaled)

\begin{tabular}{|c|c|c|c|c|c|}
\hline & Reference & Case 1 & Case 2 & Case 3 & Case 4 \\
\hline \multicolumn{6}{|l|}{ Fuel input, MWth } \\
\hline - incineration boiler & 92.00 & 92.00 & 92.00 & 92.00 & 92.00 \\
\hline - gas turbine & 0.00 & 100.14 & 101.39 & 48.44 & 104.73 \\
\hline Total & 92.00 & 192.14 & 193.39 & 140.44 & 196.73 \\
\hline MSW share, $\%$ & 100.00 & 47.88 & 47.57 & 65.51 & 46.76 \\
\hline Natural gas share, \% & 0.00 & 52.12 & 52.43 & 34.49 & 53.24 \\
\hline \multicolumn{6}{|l|}{ Power output, MWe } \\
\hline - steam turbine & 22.92 & 46.46 & 46.92 & 36.89 & 47.79 \\
\hline - gas turbine & 0.00 & 31.96 & 32.37 & 15.48 & 33.44 \\
\hline Total & 22.92 & 78.42 & 79.29 & 52.36 & 81.23 \\
\hline \multicolumn{6}{|l|}{ Efficiency, \% } \\
\hline - based on total input & 24.91 & 40.81 & 41.00 & 37.28 & 41.29 \\
\hline - based on MSW & 24.91 & 28.64 & 28.88 & 29.54 & 29.10 \\
\hline $\begin{array}{l}\text { Specific surface area } \\
\mathrm{m}^{2} / \mathrm{MWe}\end{array}$ & 294 & 710 & 686 & 340 & 518 \\
\hline
\end{tabular}

Since the prime objective of a waste incineration plant is to process waste, the natural gas share should be limited, while maintaining a high efficiency. On this basis Case 3 represents a good match between the MSW fraction in the total fuel input and the plant efficiency. The waste share in this case is $65 \%$, nonetheless, the plant efficiency is as high as $37.3 \%$.

Excluding the gas turbine part, waste-based efficiency can be defined as the ratio between the power generated by the MSW combustion and the MSW fuel input. To determine the first term the gas turbine share should be subtracted from the total power production. This share can be found by multiplying the gas turbine fuel input by a combined-cycle efficiency, so that the expression for the MSW-based efficiency becomes:

$$
\eta_{M S W}=\frac{P_{T O T A L}-F_{N G} \cdot \eta_{C C}}{F_{M S W}}
$$

When $52 \%$ is taken as the combined-cycle efficiency, the calculated MSW-based efficiency varies between $28.6 \%$ for Case 1 and $29.5 \%$ for Case 3. In the best case, Case 3, this means an increase of $4.6 \%$ points in comparison to the reference.

The effect of integration can be illustrated, if the gross efficiencies of the cases are plotted against the MSW fraction in the total fuel input together with the mean efficiency of separate plants (Fig. 5). The latter represents a line between two extremes: a combined cycle plant that operates on $100 \%$ natural gas and has an efficiency of $52 \%$, and a waste incineration plant (the reference case) that processes $100 \%$ waste at $24.9 \%$ efficiency. The benefits of integration are especially noticeable in Case 3: while Case 1 and Case 4 stand out above the line by 2.2 and 2.3 percentage points respectively, Case 3 shows a $3.6 \%$ advantage. Case 2 is not shown due to a minor distinction from Case 1. The values of the integration advantage are, of course, different, at other levels of the combined-cycle plant efficiency. 


\section{Gross efficiency, \%}

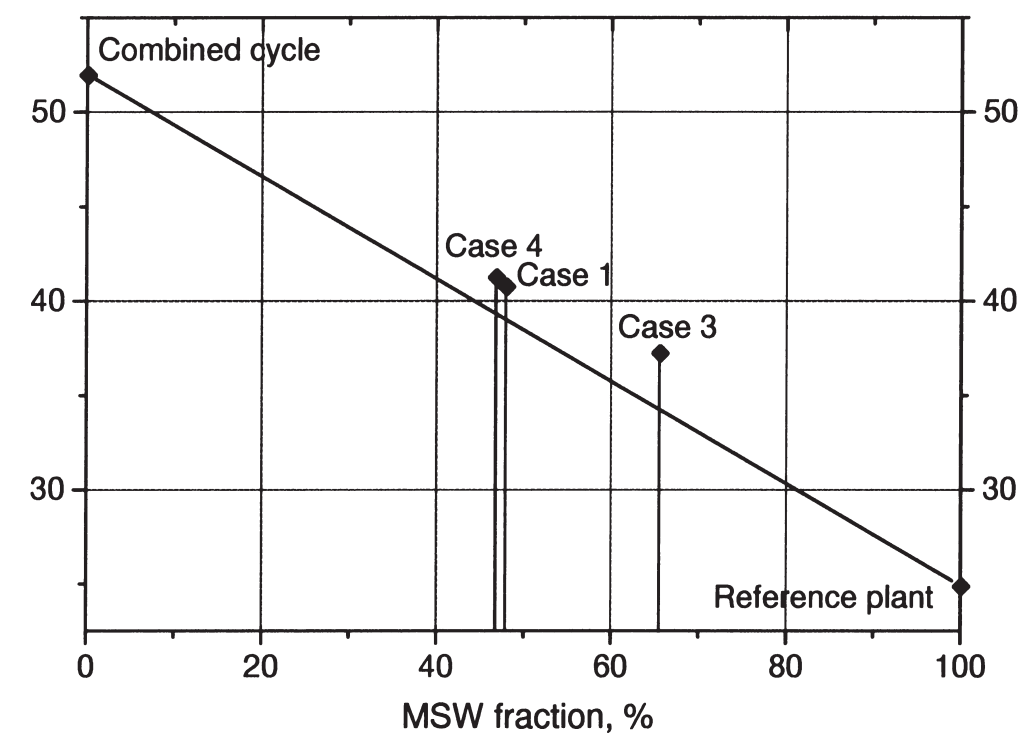

Fig. 5. The MSW fraction in the total fuel input versus gross efficiency.

Considering the total boiler surface area, all integrated schemes require a larger surface than the conventional incineration plant. In Table 3 the surface area is expressed in specific units, $\mathrm{m}^{2} / \mathrm{MW}$. As is seen from the table, the schemes, where the incineration plant operates in parallel with an HRSG, require twice as much area as the reference plant. In Case 3, which has only a superheater, the specific surface area is just $15 \%$ larger than that of the reference. The hybrid scheme, Case 4 , exceeds the reference by $76 \%$.

A comparison of the MSW fraction in the fuel input, the specific boiler area, and the total plant efficiency indicates that the high efficiency of Cases 1 through 4 are obtained at the expense of the gas turbine plant. This results in a lower MSW fraction in the fuel input and a larger boiler surface area. Case 3 appears to be the most advantageous among the options considered.

\section{Exergy analysis}

In addition to the conventional enthalpy-based analysis, exergy analysis was performed in order to assess the systems thermodynamically. The flow parameters (mass flow, temperature, pressure, enthalpy, chemical composition) from the GateCycle models were post-processed to obtain exergy values of the flows. The exergy of waste was calculated on the basis of its chemical composition using standard chemical exergy values given by Szargut et al. [17].

The results of exergy analysis are presented in Figs. 6-8 as Grassmann diagrams. The exergy values were calculated as a percentage of the total fuel input. The analysis showed that the largest loss of $45 \%$ occurs in the burner because of the highly irreversible nature of the combustion process (Fig. 6). The loss in the burner can be diminished to some extent by preheating the combustion air and by recycling the flue gas. The use of the gas turbine exhaust as inlet air 


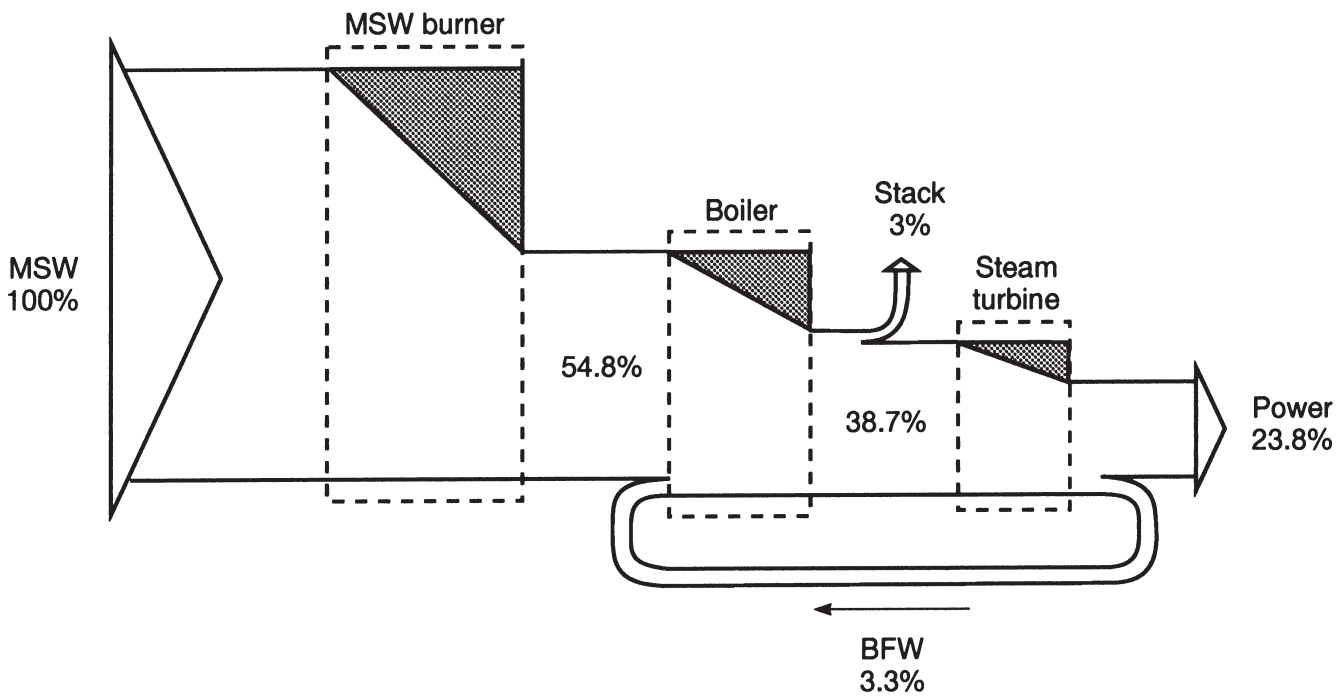

Fig. 6. Grassmann diagram of the conventional waste incinerator (Reference case).

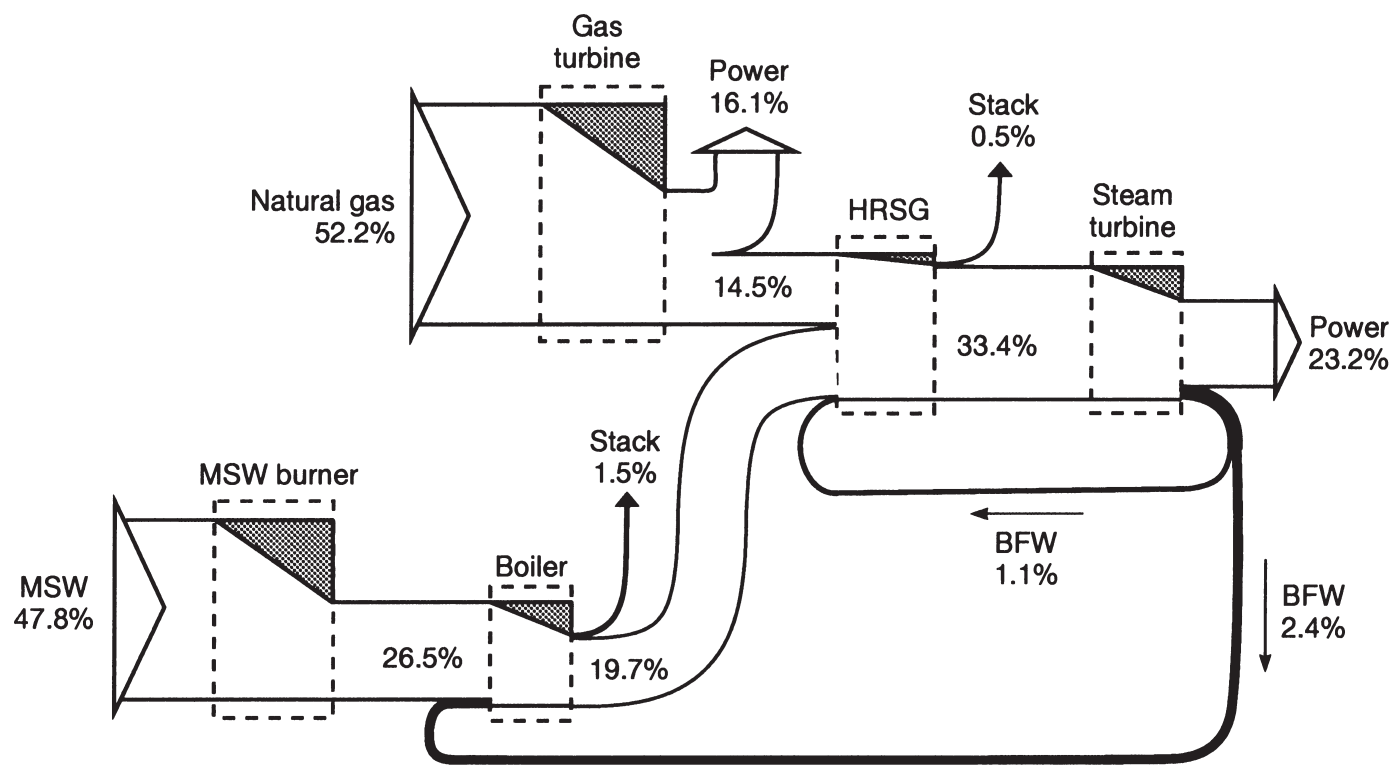

Fig. 7. Grassmann diagram of the parallel configuration (Case 1).

provides both measures. As seen in Fig. 8, this leads to an improvement of burner exergetic efficiency from a value of $54.8 \%$ to $64.2 \%$.

Another major loss was found in the boiler, owing to a large temperature difference between the combustion gases and the working medium. In the reference case about $13 \%$ of the total fuel exergy is destroyed in the boiler. This loss cannot be avoided within the incineration boiler, so 


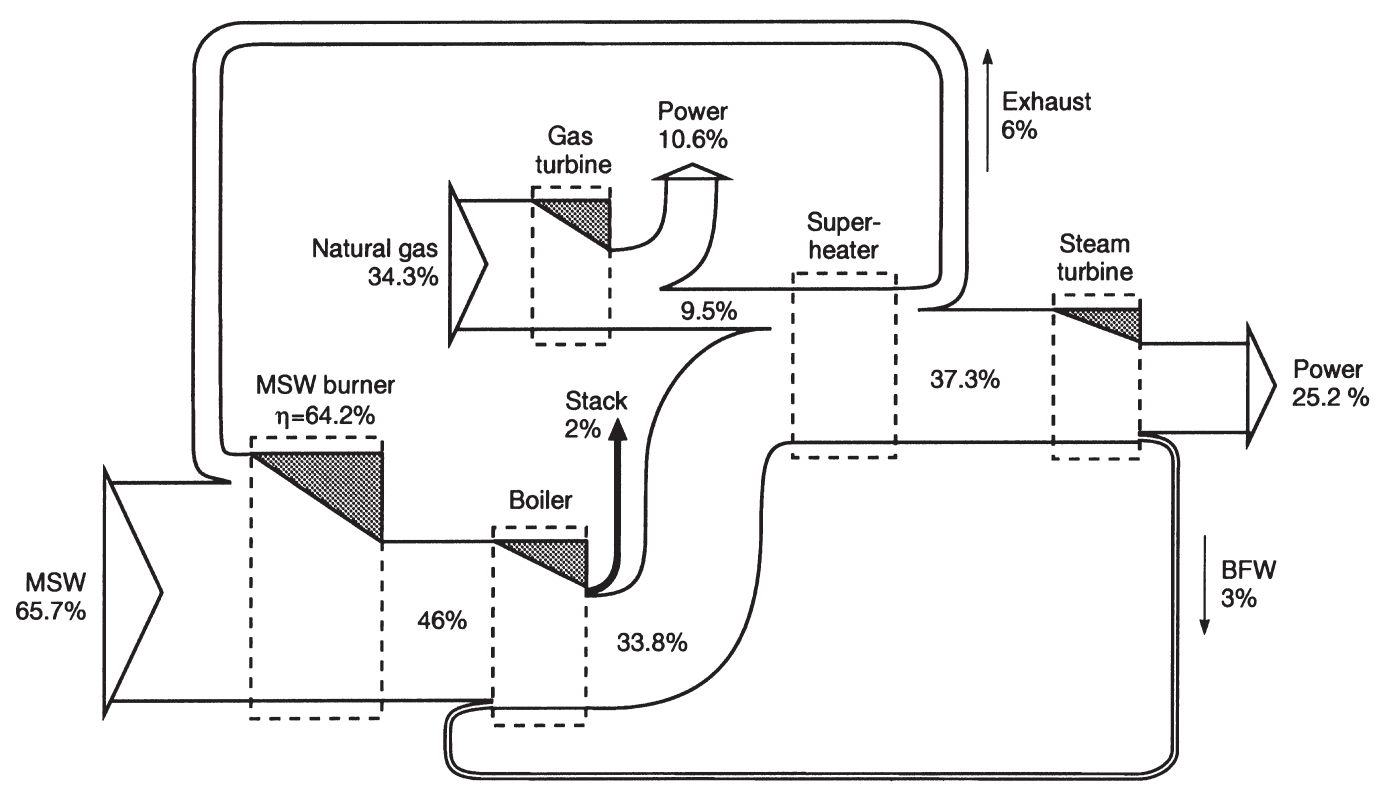

Fig. 8. Grassmann diagram of the hot windbox configuration with external superheating (Case 3).

external superheating should be applied in order to increase the exergy of the steam. If steam is superheated in an HRSG, such as in Case 1, the exergy efficiency of the plant grows from $23.8 \%$ to $39.3 \%$ (Fig. 7 ).

\section{Conclusions}

Integration of a gas turbine and an MSW incinerator results in a considerable rise in efficiency. For the configurations studied, integration added $12-15 \%$ to gross plant efficiency. This is especially noticeable in the schemes where the incineration boiler operates in parallel with the HRSG. This improvement is caused by a more effective gas turbine plant; however, a significant amount of natural gas is needed.

When compared with the mean efficiency of separate plants with respect to the MSW fraction in the total fuel input, integrated schemes showed an advantage in efficiency ranging between 2.2 and 3.6 percentage points.

Among the options studied, the hot windbox configuration with external superheating offers high efficiency along with lower natural gas consumption. In addition, this scheme has half the boiler surface area than that of other integrated options, which feature a full-scale HRSG together with an incineration boiler. However, this option requires a ducting, and an excessive gas turbine outlet pressure should be provided to pass the exhaust gas through the waste layer on the grates.

The use of the HRSG outlet gases as the secondary combustion air in the incinerator had a negligible effect on efficiency. The scheme with partial exhaust diverting was found quite effective, though its waste fraction in the total fuel input was the lowest of all the cases.

The integrated options made use of heat recovery steam generators that lead to an increased 
boiler surface area. In the parallel configurations the area can be twice as large as that of the reference. For the windbox option the increase is only $15 \%$.

Exergy analysis showed that the substantial exergy loss in the burner can be reduced by $9.4 \%$ points, if the gas turbine exhaust is applied as pre-heated combustion air. The second largest exergy loss that occurs in the incinerator boiler due to the large temperature difference is regarded as unavoidable.

\section{References}

[1] Wolpert VM. Incineration of municipal solid waste combined with energy production - last developments. Renewable Energy 1994;5:782-5.

[2] Tillman DA, Rossi AJ, Vick KM. Incineration of municipal and hazardous solid wastes. San Diego: Academic Press, 1989.

[3] Isles J. Waste incineration turns to cogeneration. Modern Power Systems 1993;13:51-5.

[4] Pirson R, Bracker G-P. The GAVI Wijster 735000 t/a waste to energy plant. Modern Power Systems 1994;14:47-51.

[5] Ramsgaard-Nielsen C. Sønderborg CHP plant burns gas and refuse. Modern Power Systems 1994;14:47-51.

[6] Anonymous. Power for ENW from Alkmaar waste incinerator. Modern Power Systems 1996;16:47-55.

[7] Grosse-Holz G. The thermal waste recycling plant of Fürth - Startup of the first scale implementation of a new technology. Paris, France: Euroforum, 1997.

[8] Stahlberg R, Feuerriegel U, Weisenburger P, Stelger F, Calaminus B. Mass and energy balances of the Thermoselect ${ }^{\circ}$ Demonstration Plant. ASME/Solid Waste Processing Division, 17th Biennial Waste Processing Conference, Atlantic City, NJ, USA, April 1996.

[9] Pfeiffer AE, Van Egmond L. Towards a new technology for the thermal treatment of municipal solid waste in the Netherlands. Power-Gen Europe'95 Conference, vols. 4 and 5, pp. 891-911, Amsterdam, The Netherlands, May 16-18, 1995.

[10] Whiting KJ. Pyrolysis and gasification technologies in Europe. Gloucestershire, UK: Juniper Consultancy Services Ltd, 1997.

[11] Andersson S. Profitable waste recovery International Power Generation 1996;16:49-50.

[12] Van Wijk G. Koppeling Warmte/Kracht met Afval (Cogeneration integrated with waste incineration). Energietechniek 1994;2:84-6.

[13] Stenzel WC, Sopocy DM, Pace SE. Repowering existing coal fired plants. International Conference on Power Engineering ICOPE-97, Tokyo, July 13-17, 1997.

[14] Pijpker BB, Keppel WE. Amsterdam to have first 140 MWe gas turbine. Modern Power Systems 1986: May.

[15] Davidse J, Roukema J. Application of gas turbine generators for preheating combustion air with conventional boilers. ASME Paper 84-GT-161, 1984.

[16] Enter Software. Gate Cycle User's Guide. Version 4.1, Menlo Park, California, 1995.

[17] Szargut J, Morris DR, Steward FR. Exergy analysis of thermal, chemical, and metallurgical processes. New York: Hemisphere Publishing, 1988. 